International Journal of Engineering \& Technology, $7(4.20)(2018) 162-165$
SPC
Website: www.sciencepubco.com/index.php/IJET
Research paper

\title{
Assessment of Using Cement Kiln Dust Stabilized Roads Subbase Material
}

\author{
${ }^{1}$ Zaid Abdulzahra Mahdi*, ${ }^{2}$ Mohammed Abbas Hasan, ${ }^{1}$ Heydar Ahmad Jasim \\ ${ }^{1}$ Roads and Transport Engineering Department/ College of Engineering/University of Al-Qadisiyah/Iraq \\ ${ }^{2}$ Civil Engineering Department/College of Engineering/University of Al-Kufa/Iraq \\ *Corresponding author E-mail: (zaid.mahdi@qu.edu.iq)
}

\begin{abstract}
The increase in the demand for cement to produce large quantities for the purpose of reconstruction produce a large amount of cement kilns dust accordingly. The cement kilns has a cementations property and it's using to treats soil. In this study, sand gravel soil (roads subbase) materials has been used to study the effect of the cement kiln dust (CKD) as a partial replacement with the natural dust of subbase till $20 \%$ by weight. Three tests procedures have been adopted which are density-moisture relationship, California bearing ratio (CBR), and unconfined compression strength (UCS). The results show significant increasing in density and optimum moisture content, $\mathrm{CBR}$, and UCS with the increasing of CKD content. Bonds induced by the pozzolanic reaction and the absorption of the free water on particles surfaces approaching each other could the cause of increasing density, forming tighten structure, and raising the CBR\% values, this reaction needs more water with increasing of CKD that could be caused increasing in the optimum moisture content. The increasing in UCS results due to stabilizing the materials by CKD increased the ability to use the CKD as alternative material for Portland cement.
\end{abstract}

Keywords: CBR, Cement Kiln Dust (CKD), Natural Aggregate, natural Dust; subbase layer.

\section{Introduction and literature review}

Cement kiln dust (CKD) is by-product material produced in Portland cement plants in large quantities, the high alkaline of CKD is preventing its reuse in cement manufacturing [1]. In Iraq, Portland cement plants produced annually about 350000 tons and available for free [2]. It is an effective alternative to cement in stabilizing soils, and the cement is more expensive than finer CKD [3], it has a cementations property which makes it an effective binder in soil. It used increasingly for stabilizing soil, and used also as additive in improvement shear strength and changing plasticity of soils [4]. For soil treatment; when increasing CKD, the maximum dry density and swell decrease while CBR values and the $\mathrm{pH}$ increase [3] also increasing in soil elasticity modulus and lowering water absorption and sorptivity [4]. Mosa et al [2] found in their research that the optimum percent of CKD to stabilize soil is $20 \%$ by soil weight which it gave optimum swelling.

Elmashad studied the effects of cement dust and the cement on compressive strength and permeability of the sandy soil, his research results show improvement of the compressive strength and durability under environmental condition, improvement of compaction, reduction of the sand permeability, and low cost of using CKD, Baghdadi et al, showed in their research the specimens of $75 \%$ and $100 \%$ CKD to sand dunes failed in the durability although it gave high strength [5].

Blending CKD with aggregate shows increasing in resilient modulus with increasing time of curing and its amount, also show a higher strength than a new constructed aggregate as subjected to repeated loads, also improvement in flexural strength [6].

\section{Materials and methods}

Materials used in this research were the whole aggregate or natural aggregate compose of sand-gravel soil, and the cement kiln dust (CKD).

The natural aggregate was limestone brought from Al-Najaf city quarries (western south of Iraq), Figure (1) exhibit the particle size distribution which is comply with the subbase layer materials specifications type "B" according to Iraqi specifications (Table R6/1) [7] as shown in Table (1), Table (2) shows the physical properties.

Cement kiln dust brought from Al-Kufa Cement factory in AlNajaf city, chemical composition shown in Table (3), the sulphate content $\left(\mathrm{SO}_{3}\right)$ was found $15.7 \%$ thus percent's of $\mathrm{CKD}$ added must not exceed $32 \%$ of total mix to satisfy the specifications requirements [7]. And when used as fines (15\% upper limit), it will be satisfied. In general, kiln dust has a larger surface area than cement due to its finer particle size distribution [1]. 


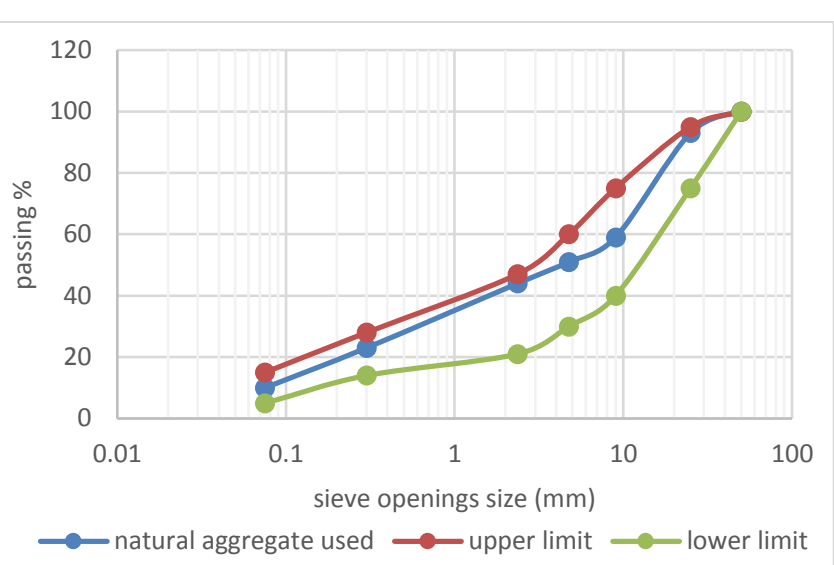

Fig.1: Particle Size Distribution of Natural Aggregate and the Limits of the Specification [7]

Table (1): The Iraqi standard specifications requirement of subbase layer materials [7]

\begin{tabular}{|c|c|c|c|c|c|}
\hline \multirow{4}{*}{ Sieve size } & \multicolumn{5}{|c|}{ Percent of passing } \\
\cline { 2 - 6 } & Type A & Type B & Type C & Type D \\
\cline { 2 - 6 } & $75 \mathrm{~mm}$ & 100 & - & - & - \\
\cline { 2 - 6 } & $50 \mathrm{~mm}$ & $100-95$ & 100 & - & - \\
\cline { 2 - 6 } & $25 \mathrm{~mm}$ & - & $95-75$ & 100 & 100 \\
\cline { 2 - 6 } & $9 \mathrm{~mm}$ & $65-30$ & $75-40$ & $85-50$ & $100-60$ \\
\cline { 2 - 6 } & $4.75 \mathrm{~mm}$ & $55-25$ & $60-30$ & $65-35$ & $85-50$ \\
\hline & $2.36 \mathrm{~mm}$ & $42-16$ & $47-21$ & $52-26$ & $72-42$ \\
\hline & $0.3 \mathrm{~mm}$ & $18-7$ & $28-14$ & $28-14$ & $42-23$ \\
\hline & $0.075 \mathrm{~mm}$ & $8-2$ & $15-5$ & $15-5$ & $20-5$ \\
\hline \multicolumn{7}{|c|}{ CBR (minimum) } & 45 & 35 & 30 & 20 \\
\hline
\end{tabular}

Table (2): The physical properties of used natural aggregate with standard specifications of tests

\begin{tabular}{|c|c|c|c|}
\hline property & Result & Specifications value & Standard tests $^{[8]}$ \\
\hline Liquid limit $\%$ & 23 & $25 \max$ & \multirow{3}{*}{ ASTM D 4318} \\
\hline Plastic limit $\%$ & 19 & & \\
\hline Plasticity index & 4 & $6 \max$ & \\
\hline Density $\left(\mathrm{Gm} / \mathrm{cm}^{3}\right)$ & 2.21 & & \multirow[b]{2}{*}{ ASTM D 1557} \\
\hline Optimum moisture $\%$ & 5.3 & & \\
\hline $\mathrm{CBR} \%$ & 37 & $35 \mathrm{~min}$ & ASTM D 1883 \\
\hline UCS (Mpa) & 6.7 & & ASTM D 1633 \\
\hline
\end{tabular}

Table (3): Chemical Composition of CKD*

\begin{tabular}{|c|c|}
\hline Table (3): Chemical Composition of CKD* \\
\hline Components & Percentage \\
\hline $\mathrm{CaCO}_{3}$ & $49.5 \%$ \\
\hline $\mathrm{Na}_{2} \mathrm{O}$ & $1.5 \%$ \\
\hline $\mathrm{K}_{2} \mathrm{O}$ & $0.5 \%$ \\
\hline $\mathrm{CaO}+\mathrm{free} \mathrm{CaO}^{*}$ & $27.57 \%$ \\
\hline $\mathrm{SO}_{3}$ & $15.73 \%$ \\
\hline $\mathrm{SiO}_{2}$ & $12.58 \%$ \\
\hline $\mathrm{Al}_{2} \mathrm{O}_{3}$ & $1.86 \%$ \\
\hline $\mathrm{Fe}_{2} \mathrm{O}_{3}$ & $1.44 \%$ \\
\hline Total Dissolved Solids (TDS) & $6.13 \%$ \\
\hline Loss On Ignition (LOI) & $15.82 \%$ \\
\hline Free CaO & $13 \%$ \\
\hline
\end{tabular}

*A.M. Mosa et al. [2]

In this paper, sand-gravel soil (roads subbase) materials has been used to study effect of the cement kiln dust as a partial replacement with the natural dust (fines or materials finer than $0.075 \mathrm{~mm}$ ) of subbase in $5,10,15$, and $20 \%$ by weight. Three tests procedures have been adopted which are compaction, CBR, and unconfined compression strength.

Paper aims to make use of wastes by-products materials in strengthen the subbase and to find alternatives to use as base layer.

\section{Results and discussion}

\subsection{Maximum density and optimum moisture content}

Figure (2) illustrates the maximum dry density of natural aggregate mixed with different CKD content, there is a significant in- creasing in density as comparing with the content of CKD this could be attributed to some reasons, 1-the high surface area and fineness of CKD to fills the voids [1,2], 2-specific gravity of CKD as compare it with clays specific gravity, 3-reduction the plasticity, and 4-adsorption by the pozzolanic reaction absorb the free water on particles surface approaching each other. The pozzolanic reaction and the high surface area and fineness of CKD, the water absorption increased with the increasing of binder to maintain consistency in a constant that is caused increasing the in optimum moisture content [1] as shown in Figures (3) and (4).

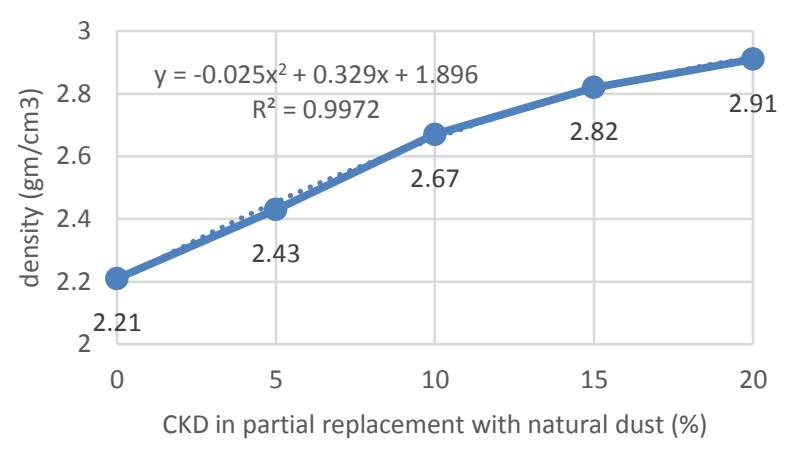

Fig. 2: Relationship between the maximum dry density and CKD Content

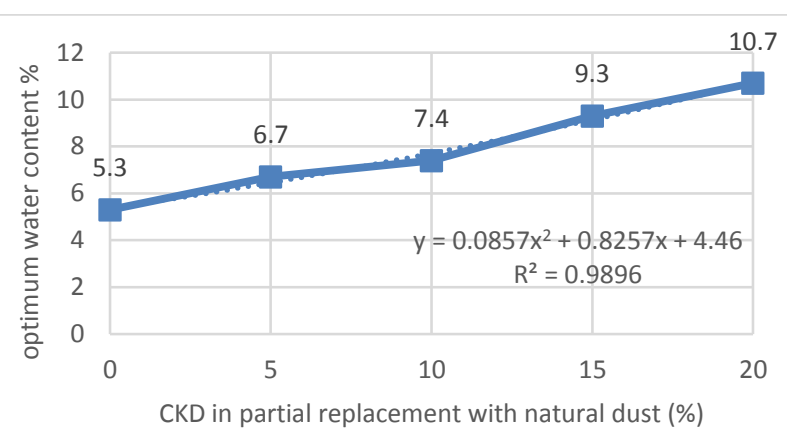

Fig.3: Illustrates the effect of the CKD content on the optimum moisture content values

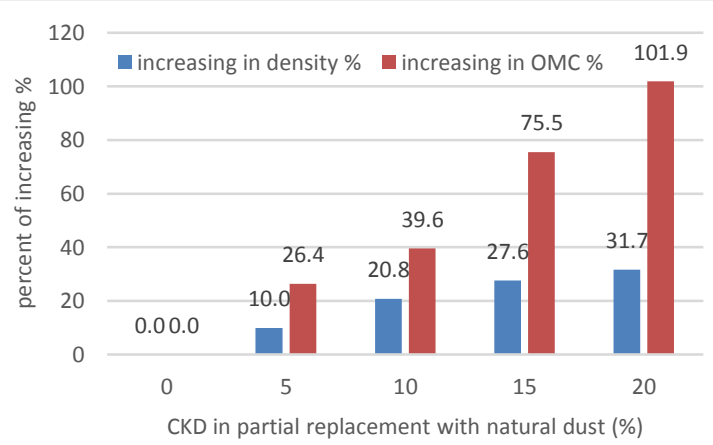

Fig. 4: Percent of Increasing in Both Density and OMC Influenced By CKD Content.

\subsection{California Bearing Ratio (CBR \%)}

The CBR\% values were clearly increased with CKD increasing as shown in Figures 5 and 6 , that is attributed to forming bonds by the pozzolanic reaction given strength and tighten structure due to some reasons like 1-presence of free lime and low alkalis [2], 2increasing in density, 3-absorbing water by CKD reactions and cation exchanges reforming structure [1], and 4-the plasticity reduction induced to the effect of high lime with low alkalis [2] and effect of silica which works as sand. Moreover, CKD has amount of alkalis which contains the major stabilizing agent is the calcium required for stabilizing the aggregates [6] which reduce the deflection during applying loads [10]. 
Little amount of CKD (about 16\% from natural fines which was $10 \%$ from total sample weight) make the mix accepted as base layer from CBR\% point of view according the Iraqi specifications requirements as shown in Figure (5). As the CBR value increasing, the layer coefficient $\left(\mathrm{a}_{\mathrm{i}}\right)$ will increase consequently and the layers thickness decreases [9] this lead to enhancement the pavement performance and increasing service life, and reducing the deflection [10] after soil stabilized which leads to reduce the maintenance cost.

As comparing the CBR results with Mohsen and Jawad [11] and Ghani et al [10] researches which they had used the same subbase materials (natural aggregate type B from the same quarry have closely properties and particles gradation), their CBR results revealed that adding cement reached to $8 \%$ by the total weight was close to this research results although of high content of cement compare to with CKD used, it could be due to they left the natural dusts or fines, increased amount of fines, and the high surface area and fineness of CKD to fill the voids comparing to the cement.

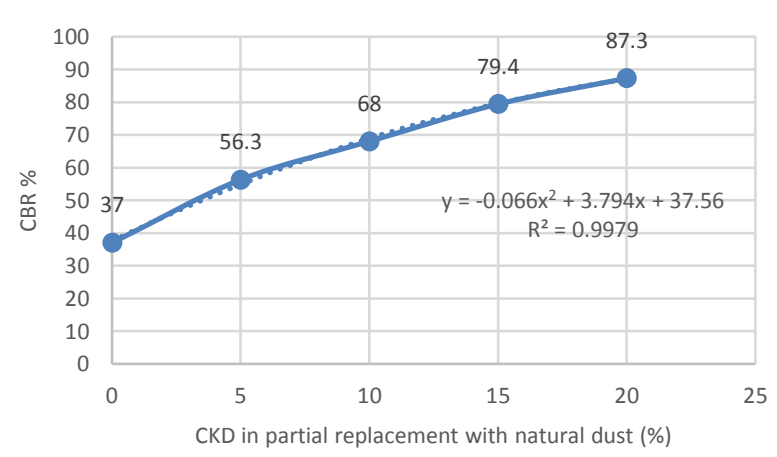

Fig. 5: The effect of CKD content on CBR values

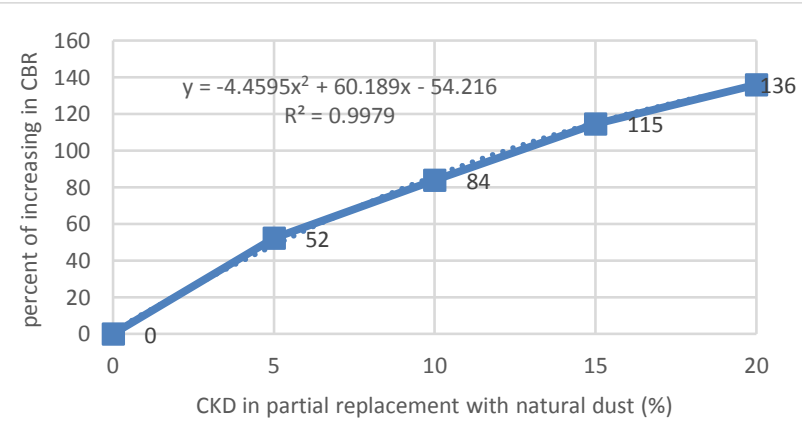

Fig. 6: Percent of increasing in CBR values as influenced by $\mathrm{CKD}$ content

\subsection{Unconfined Compression Strength}

Under unconfined situations of subbase materials, the results of the UCS assessment revealed increasing in the strength by increasing in CKD content as shown in Figure (7), it's due to the pozzolanic reactions forming bonds with presence of the calcium agent in CKD and high free lime in CKD with low alkalis [2], this result reveals that there is ability to use the CKD as alternative material for cement. Figure (8) shows a significant increasing in UCS values especially with more than $10 \%$ CKD.

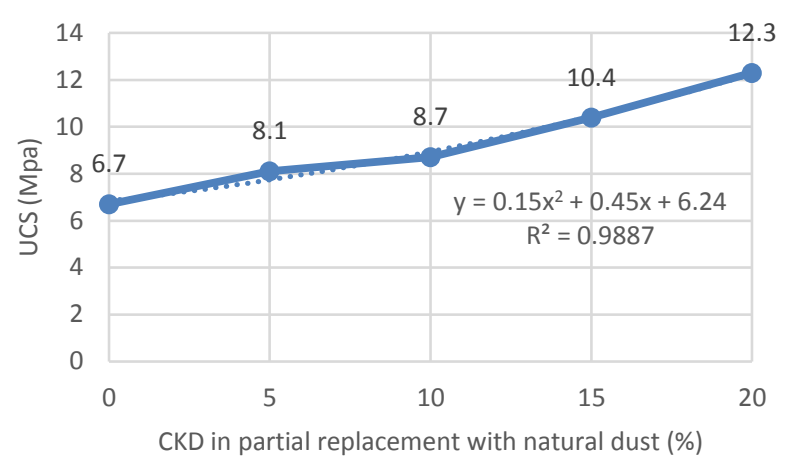

Fig. 7: UCS values as influenced by CKD content

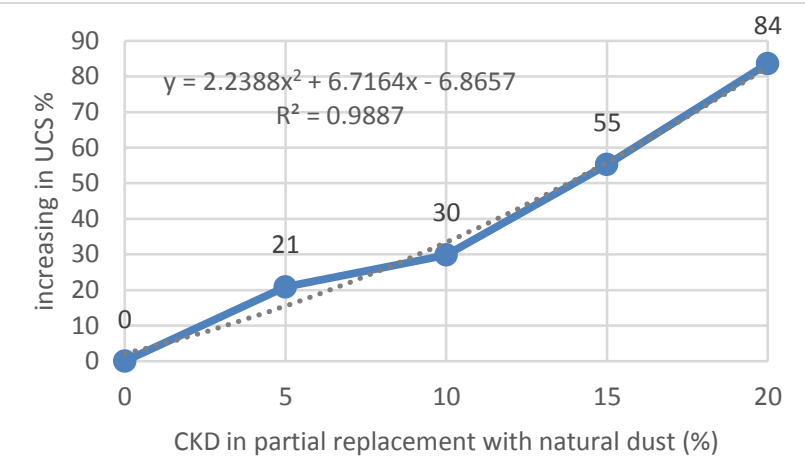

Fig. 8: Percent of increasing in UCS as influenced by CKD content

\section{Economic evaluation}

To evaluate the adding CKD to natural aggregate from economical point of view the selecting the most economical design and fixing some variables when comparing as shown in Table (4), taking the modulus of asphaltic surface and base layers, and the two cases of subbase (natural and treated with CKD in $20 \%$ from fines content) then using the AASHTO method to find thicknesses of the layers by adopting the design structural number is 5 .

Table (4): Comparison between two designs structures

\begin{tabular}{|c|c|c|c|}
\hline & \multicolumn{3}{|c|}{ Case 1: not stabilized subbase } \\
\hline layer & Modulus (psi) & Layer coefficient (a) & Thickness (inch) \\
\hline Surface & $340 *$ & 0.38 & $2 * *$ \\
\hline Base & $230 *$ & 0.32 & $4 * *$ \\
\hline Subbase & $\mathrm{CBR}=37 \%$ & 0.12 & 25 \\
\hline & \multicolumn{3}{|c|}{ Case 2: stabilized subbase } \\
\hline layer & Modulus (psi) & Layer coefficient (a) & $\begin{array}{l}\text { Thickness } \\
\text { (inch) }\end{array}$ \\
\hline Surface & $340 *$ & 0.38 & $2 * *$ \\
\hline Base & $230 *$ & 0.32 & $4 * *$ \\
\hline Subbase & $\mathrm{CBR}=87 \%$ & 0.136 & 22 \\
\hline
\end{tabular}

* From Mutlag [12] and Jasim [13]

** recommended by AASHTO as minimum limits [14]

Table (5): The materials price in Iraq [15]

\begin{tabular}{|c|c|}
\hline Material & Cost $\left(\mathrm{IQD} / \mathrm{m}^{3}\right)$ \\
\hline Asphalt concrete surface & 300,000 \\
\hline Asphalt concrete base & 200,000 \\
\hline Subbase & 21,000 \\
\hline
\end{tabular}

Because the CKD is priceless and used in very little amount (about 2\% from of total sample) it has the same price as natural aggregate subbase material as shown in Table (5). Table (6) shows the construction cost, thickness, and reduction in cost. Reduction in total thickness was $9.6 \%$, and in subbase thickness $12 \%$, while the reduction in total initial cost $1.9 \%$ and $12.7 \%$ reduction in subbase cost. 
Table (6): Shows the construction cost and thickness

\begin{tabular}{|l|l|l|l|}
\hline \multicolumn{3}{|c|}{ Cost (IQD) } & Thickness (inch) \\
\hline \multicolumn{3}{|c|}{ Case 1: not stabilized subbase } \\
\cline { 1 - 2 } Surface & 15,000 & \multirow{2}{*}{41,300} & 31 \\
\hline Base & 20,000 & \multirow{2}{*}{ Case 2: stabilized subbase } \\
\hline Subbase & 6,300 & \multirow{2}{*}{40,500} & 28 \\
\hline \multicolumn{3}{|c|}{} & \\
\hline Surface & 15,000 & 28 \\
\hline Base & 20,000 & \\
\hline Subbase & 5,500 &
\end{tabular}

\section{Conclusions and recommendations:}

The replacement of natural dust with by CKD has a positive result in improvement of strength of natural aggregate subbase materials such used, it's clearly improves the unconfined compression strength and California bearing ratio. The percent more than $15 \%$ of CKD make increasing in CBR and UCS to more than $115 \%$ and $55 \%$ respectively. Little amount of CKD (about $16 \%$ from natural fines which was $10 \%$ from total sample weight) make the mix accepted as base layer from CBR\% point of view according the Iraqi specifications requirements, results refer that there is ability to use the CKD as alternative material for cement. Both density and optimum moisture content were clearly increased when the CKD content increased with little amounts.

Moreover, it raises the layer coefficient which led to decrease the layer thickness, this reduction was $12 \%$ in subbase thickness while the reduction in subbase cost was $12.7 \%$. It recommended to use CKD to stabilize and improve the subbase materials and study effect of raising its percent.

\section{References}

[1] EL Sharif M. Abdel Aziz, Ahmed K. Altohamy, and Ahmed R. Towfeek, " physical and chemical properties for stabilized sand using cement kiln dust", Journal of Engineering Sciences, Assiut University, Vol. 38, No. 3 (2010), pp.655-669

[2] Ahmed Mancy Mosa, Amer Hasan Taherb, and Layth A. AlJaberib," Improvement of poor subgrade soils using cement kiln dust", Case Studies in Construction Materials 7 (2017) 138-143.

[3] Ramzi Taha, Amer Al-Rawas, Ali AI-Harthy, and Hilal AI-Siyabi," use of cement by-pass dust in soil stabilization", Engineering Journal of the University of Qatar, Vol. 14,(2001), pp 61-76.

[4] J. Sudheer Kumar and Upma Janewoo," Stabilization of Expansive Soil with Cement Kiln Dust and RBI Grade 81 at Subgrade Level", Geotech Geol Eng, Springer International Publishing Switzerland (2016) 34:1037-1046.

[5] Laith Jawad Aziz and Hamid Athab Eedan, "Improvement of the Fluvial Soil Characteristics of Al-Kufa River by Using Cement Dust", International Journal of Engineering Research \& Technology (IJERT), Vol. 2 Issue 11, (2013), pp 2619-2633.

[6] Joe W. Button" kiln dust for stabilization of pavement base and subgrade materials", (2003), Texas A\&M University System College Station, Texas, united states

[7] SCRB, State Corporation for Roads and Bridges, "standard specifications for roads and bridges", design and studies department, Ministry of housing and construction, Republic of Iraq.

[8] ASTM, (2009),"American Society for Testing and Materials", united states.

[9] Shojaei Baghini, M., et al., "the potentials of portland cement and bitumen emulsion mixture on soil stabilization in road base construction", Journal of Technology, (2013). 65(2): p: 67-72.

[10] Rasha. Abd Al-Redha Ghani, Mohammed A. Al-Jummaily and. Ahlam K. R. Al-Zerjawi," study of cement treated base agreagate properties for pavement structure", International Journal of Information Research and Review, January, (2018), vol. 05, Issue, 01, pp.5093-5100.

[11] Abbas Talib Mohsen and Tawfik Aamir Jawad," influence of cement as additive in improving granular materials properties", Kufa Journal of Engineering, Vol.1, No.2, 2010, pp: 175-184.

[12] Salam Adil Mutlag, "effect of binder layer properties on Flexible pavement in Iraq", Al-Qadisiya Journal for Engineering Sciences, Vol. 5, No. 4, Year 2012, pp: 466-476.

[13] Ahmed Abbas Jasim, "Effect of Pavement Layers Properties on Optimum Performance by Mechanistic-Empirical Method", Jour- nal of Babylon University/Engineering Sciences/ No. (2)/ Vol. (23): 2015.

[14] AASHTO, AASHTO Guide for Design of Pavement Structures. 1993, Washington, D.C: American Association of State Highway and Transportation Officials.

[15] Zaid AbdulZahra Mahdi, "Improvement of the Structural Characteristics of the Recycled Asphalt Pavement in Iraq", A Master degree thesis Submitted to the Highway and Transportation Engineering Department, College of Engineering, AL-Mustansiriya University, 2013, Baghdad, Iraq. 